\title{
Deep-ocean flow-speed changes linked to the NAO through Labrador Sea convection
}

\author{
Karin P. Boessenkool' ${ }^{1}$, I.R. Hall ${ }^{1}$, H. Elderfield ${ }^{2}$ and I. Yashayaev ${ }^{3}$ \\ 'School of Earth, Ocean and Planetary Sciences, Cardiff University, UK; BoessenkoolK@cardiff.ac.uk; Hall@cardiff.ac.uk; ${ }^{2}$ Department of Earth \\ Sciences, University of Cambridge, UK; ${ }^{3}$ Bedford Institute of Oceanography, Fisheries and Oceans, Canada
}

The Atlantic Meridional Overturning Circulation (AMOC) is important for the stability of the climate of northwest Europe, with models demonstrating that alterations in its strength and structure can lead to abrupt climate change (Rahmstorf, 2002). The Gulf Stream and its extension, the North Atlantic Current (Fig. 1a), are surface elements of the MOC while North Atlantic Deep Water (NADW) is its main southbound constituent. The densest components of NADW are formed in the Nordic Seas where cold, salty water sinks. IcelandScotland Overflow Water (ISOW) and Denmark Strait Overflow Water (DSOW) jointly comprise the cold, dense overflows from the Nordic Seas across the GreenlandScotland Ridge (GSR). The strength of the GSR overflows seems to be modulated by the North Atlantic Oscillation (NAO) (e.g., Biastoch et al., 2003), which is the dominant mode of atmospheric variability in the North Atlantic sector. As ISOW descends into the deep North Atlantic, its volume nearly triples due to entrainment of salty, warm Atlantic subpolar-mode water (SPMW; Fig. 2) and fresher Labrador Sea Water (LSW; Hansen and Østerhus, 2000). ISOW freshened (Dickson et al., 2002) and the overflow weakened (Hansen et al., 2001) during the last four decades of the 20th century. However, it is not known if these changes fall within the natural variability of the system.

\section{ISOW flow speed changes and the NAO}

We reconstructed past changes in the near-bottom flow speed of ISOW using the paleocurrent proxy 'sortable' silt mean grain size $(\overline{\mathrm{SS}})$ - the mean grain size of the 10-63 $\mu \mathrm{m}$ terrigenous silt fraction (McCave et al., 1995). The flow of ISOW has built up extensive sediment drifts, such as the Gardar Drift along the eastern slope of Reykjanes Ridge, that are well suited for this method (Bianchi and McCave, 2000). Sediment box core RAPID-21-12B (Fig. 1), recovered from the southern Gardar Drift, was dated using the ${ }^{210} \mathrm{~Pb}$ method (Boessenkool et al., 2007). We constructed a continuous $\overline{S S}$ record through the period 1770-2004 AD, where each sample represents an integrated signal of $2.2 \pm 0.2 \mathrm{yr}$. The decadal trends shown in Figure $1 \mathrm{~b}$ reflect changes in ISOW vigor as it passed over the eastern flank of Reykjanes Ridge (ISOW ${ }_{R R^{\prime}}$ Boessenkool et al., 2007).

The NAO is usually expressed as an index of the normalized sea-level pressure difference between the Azores High and Iceland Low pressure areas. To explore the interrelation between $\mathrm{ISOW}_{\mathrm{RR}}$ flow speed and the NAO, the winter (December-March) index of the NAO (Jones et al., 1997) was smoothed using a 7-year filter because the ocean's inertia acts as a natural filter for higher-frequency changes occurring in the atmosphere. Statistical analysis (cf. Mudelsee, 2003) revealed a significant, inverse linear correlation between the $\overline{\mathrm{SS}}$ record and the NAO index on decadal timescales (Boessenkool et al., 2007), with the strongest correlation $\left(r_{x y}=-0.42\right)$ for the period 1885-2004 AD ( $n=55)$. It suggests that the flow of ISOW RR $_{\text {has }}$ been persistently strongest during low NAO index phases.

\section{Hydrographic timeseries and deep-flow speed}

To explain this relation, we first compared flow-speed variations and the NAO index with hydrographic time series of $\mathrm{ISOW}_{\mathrm{RR}}$. We focused on the period of the pronounced NAO reversal, from an extremely negative index state in the 1960's to dominantly positive values through the 1990's (Fig. 1b), where the $\overline{S S}$ record (Fig. 1c) declines significantly, suggesting a

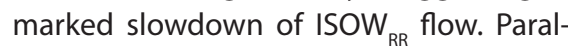
lel patterns in the $\overline{S S}$ record and two ISOW salinity time series (Fig. 1c) suggest that changes in ISOW flow speed and salinity are coordinated. Furthermore, consideration of oceanographic changes between the two NAO extremes showed (1) a density decrease of $\mathrm{ISOW}_{R R}$ (Fig. 2), and (2) a $\sim 25 \%$ reduction in volume transport of total deep southward flow over the eastern Reykjanes Ridge (Boessenkool et al., 2007), similar to the decrease in ISOW passing through the Charlie-Gibbs Fracture Zone (CGFZ, Fig. 1a; Saunders, 1994). It is likely that variations in ISOW ${ }_{R R}$ vigor are caused by changes in any of its constituents: ISOW proper, SPMW and LSW. Over the four decades spanning the NAO reversal, all three components freshened (Dickson et al., 2002; Curry and Mauritzen, 2005; Lazier et al., 2002). However, while ISOW and SPMW became less dense, LSW not only reached its freshest but also its coldest and densest state ever recorded in 1993/94 (Dickson et al., 1996; Lazier et al., 2002), after a number of high-NAO-index winters (1990-94) led to exceptionally vigorous and deep convection in the Labrador Sea. The unprece-

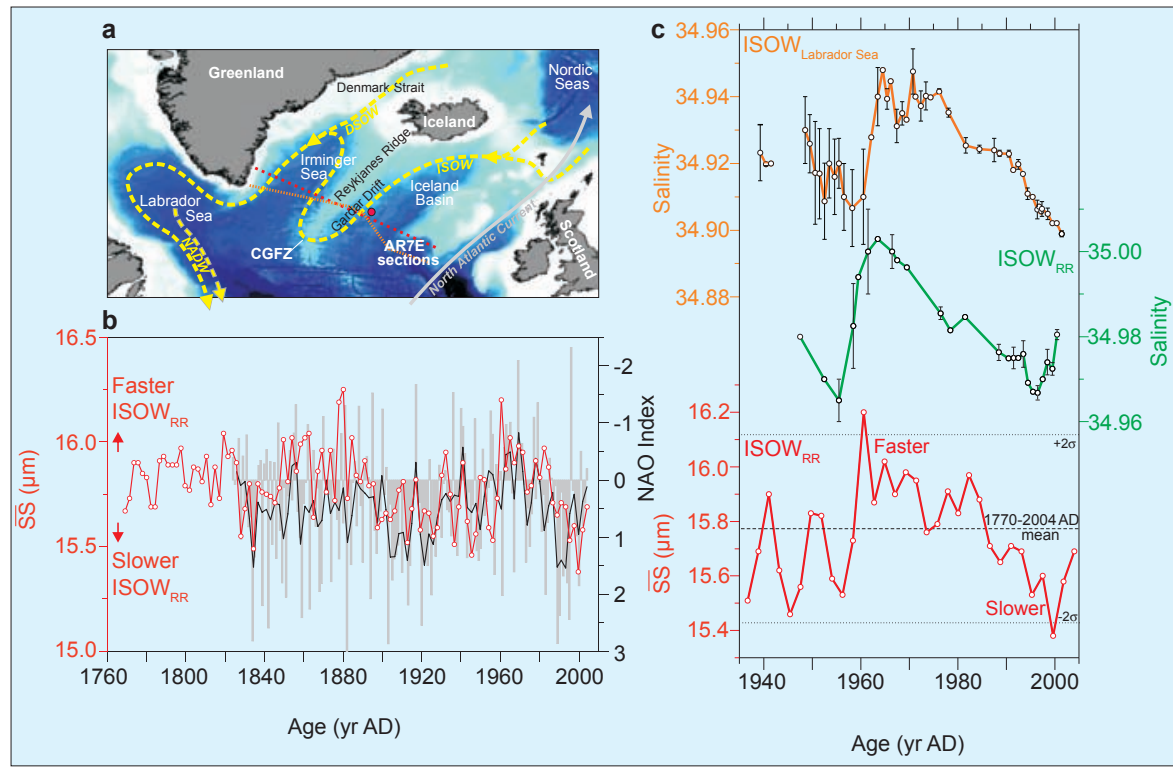

Figure 1:a) Map of North Atlantic Ocean with schematic pathway of ISOW (yellow line), DSOW (yellow line), NADW (yellow line) and the North Atlantic Current (grey line). Location of RAPID-21-12B core indicated (red circle), and hydrographic sections (AR7E section) of Fig. 2 are shown for 1966 (red, dashed) and 1994 (orange, dotted). Location of Charlie Gibbs Fracture Zone (CGFZ) is also indicated; $\boldsymbol{b}$ ) Evidence of linear relationship between near-bottom

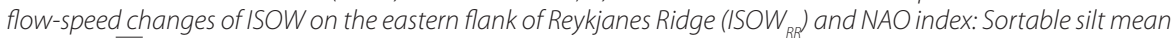
grain size (SS) record of core RAPID-21-12B (red); winter NAO index (grey bars, reverse scale), 7-year smoothed NAO index (black); c) Salinity time series of ISOW in Labrador Sea (orange) and eastern Reykjanes Ridge (green), SS record of core RAPID-21-12B (red). Figure modified from Boessenkool et al., 2007. 


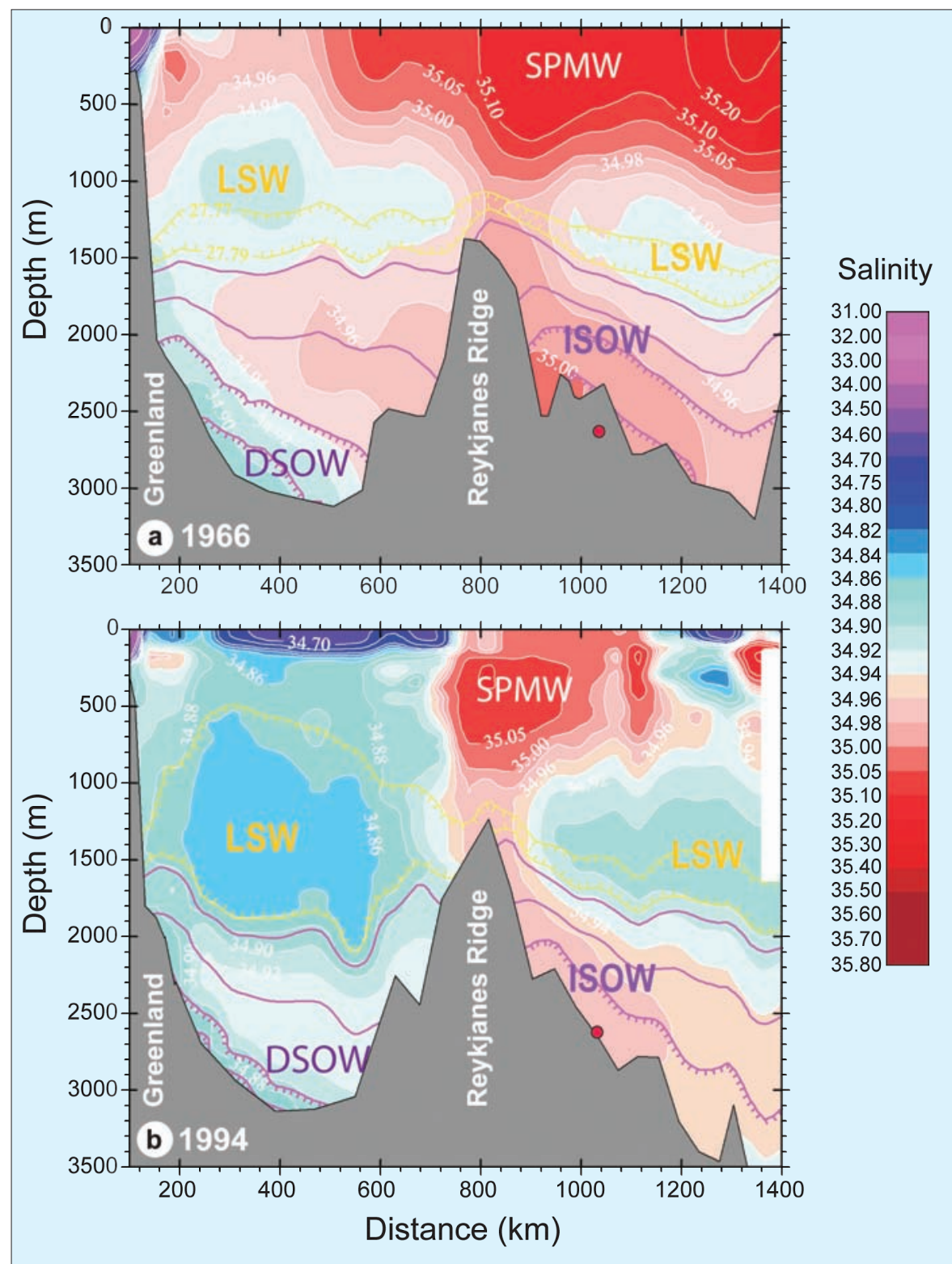

Figure 2: Salinity and density profiles on trans-Atlantic hydrographic sections (Fig. 1a; section AR7E, World Ocean Circulation Experiment) for a) 1966 and b) 1994; Red circles indicate (projected) core location. Yellow and magenta contours are isopycnals $\left(\mathrm{kg} \mathrm{m}^{-3}\right.$ ) indicating characteristic densities of intermediate (yellow, LSW) and deep (magenta, ISOW and DSOW) waters. Figure modified from Boessenkool et al., 2007.

dented large, dense body of LSW invaded the intermediate depths of the subpolar North Atlantic within 2-5 years (Fig. 2b; Yashayaev et al., 2007). By contrast, LSW production, density and export were greatly reduced during the 1960's (Fig. 2a), after several low-NAO-index winters (Dickson et al., 2002).

Some model studies suggest convective changes in the Labrador Sea may be more important in the production of NADW than variations in the GSR overflows (Cheng and Rhines, 2004; Eden and Jung, 2001); particularly, the modeled overflows weaken when LSW formation intensifies. We suggest that the larger volume of denser and fresher LSW that built up over the NAO transition played a major role in slowing the deep flow of ISOW ${ }_{R R}$. Mechanisms for this slowdown could include: First, a reduction of the density gradient in the Iceland Basin; this would likely diminish transport across the ISR, as has

\section{Implications for monitoring future AMOC stability}

Most hydrographic time series started in the 1960's. Although pre-1960's salinity data are sparse, they are again closely mirrored by the $\overline{S S}$ record (Fig. 1c). Only the extreme values for 1961 and 2000 in the $\mathrm{ISOW}_{\mathrm{RR}}$ flow speed record lie outside the $2 \sigma$ to have had the reverse effect on ISOW volume (Curry and Mauritzen, 2005), flow speed and salinity (Fig. 1c). range of the 230-year record. Thus, most of the recent changes in ${ } S_{S O} W_{R R}$ flow cannot be distinguished from natural variability in the deep flow. Average values for both ISOW $_{R R}$ flow speed and salinity time series were recorded during the mid-1970's, suggesting that this period, coupled with the 1960-2000 range, might provide useful reference levels for future oceanographic changes.

In conclusion, our paleocurrentspeed record suggests that decadal-scale changes in ISOW ${ }_{R R}$ vigor during the past 230 years are significantly, inversely correlated with the NAO index. Property changes of ISOW ${ }_{R R}$ constituents have previously been attributed to NAO forcing. Many of them theoretically work in the same direction, either slowing down or speeding up ISOW $_{\text {RR }}$ flow. It is, therefore, difficult to ascribe the observed flow speed changes to a single cause. Nevertheless, our data suggest that the NAO influences deep-ocean current speeds in the North Atlantic, and that LSW could rapidly transfer NAO forcing to the deep ocean.

\section{Note}

Data will be available from the NOAA Paleoclimatology website at:

www.ncdc.noaa.gov/paleo/paleo.html

\section{Acknowledgements}

We thank H. Medley for laboratory assistance. M. Bersch kindly supplied hydrographic data. We are grateful to the master, officers, crew and scientific party of RRS Charles Darwin cruise CD159. This work was supported by the U.K. Natural Environment Research Council Rapid Climate Change Programme.

\section{References}

Boessenkool, K.P., Hall, I.R., Elderfield, H. and Yashayaev, I., 2007: North Atlantic climate and deep-ocean flow speed changes during the last 230 years, Geophysical Research Letters, 34: L13614, doi:10.1029/2007GL030285

Dickson, B. Yashayaev, I., Meincke, J., Turrell, B., Dye, S. and Holfort, J., 2002: Rapid freshening of the deep North Atlantic Ocean over the past four decades, Nature, 416: 832-837.

Hansen, B., Turrell, W.R. and Østerhus, S., 2001: Decreasing overflow from the Nordic seas into the Atlantic Ocean through the Faroe Bank channel since 1950, Nature, 411(6840): 927-930.

McCave, I.N., Manighetti, B. and Robinson, S.G., 1995: Sortable silt and fine sediment size composition slicing: parameters for palaeocurrent speed and palaeoceanography, Paleoceanography, 10(3): 593-610.

Yashayaev, I., Bersch, M. and Van Aken, H.M., 2007: Spreading of the Labrador Sea Water to the Irminger and Iceland basins, Geophysical Research Letters, 34: L10602, doi:10.1029/2006GL028999.

For full references please consult:

www.pages-igbp.org/products/newsletter/ref2008_1.html 